University of Nebraska - Lincoln

DigitalCommons@University of Nebraska - Lincoln

$12-23-2004$

\title{
Isolating Adult Psychological Correlates of Witnessing Parental Violence: Findings from a Predominantly Latina Sample
}

Corrie A. Davies

University of Nebraska-Lincoln, cdavies2@unl.edu

David DiLillo

University of Nebraska-Lincoln, ddilillo@unl.edu

Isaac G. Martinez

Our Lady of the Lake University

Follow this and additional works at: https://digitalcommons.unl.edu/psychfacpub

Part of the Psychiatry and Psychology Commons

Davies, Corrie A.; DiLillo, David; and Martinez, Isaac G., "Isolating Adult Psychological Correlates of Witnessing Parental Violence: Findings from a Predominantly Latina Sample" (2004). Faculty Publications, Department of Psychology. 124.

https://digitalcommons.unl.edu/psychfacpub/124

This Article is brought to you for free and open access by the Psychology, Department of at DigitalCommons@University of Nebraska - Lincoln. It has been accepted for inclusion in Faculty Publications, Department of Psychology by an authorized administrator of DigitalCommons@University of Nebraska - Lincoln. 
Published in Journal of Family Violence, Vol. 19, No. 6 (December 2004), pp. 377-385. DOI:

10.1007/s10896-004-0682-9 Copyright (C) 2004 Springer Science+Business Media, Inc. Used by permission.

\title{
Isolating Adult Psychological Correlates of Witnessing Parental Violence: Findings from a Predominantly Latina Sample
}

\author{
Corrie A. Davies, Department of Psychology, University of Nebraska-Lincoln \\ David DiLillo, Department of Psychology, University of Nebraska-Lincoln (Corresponding author: e-mail: ddilillo@unl.edu) \\ Isaac G. Martinez, Department of Psychology, Our Lady of the Lake University, San Antonio, Texas
}

\begin{abstract}
This study examined the relationship between childhood exposure to parental violence and adult psychological functioning in a sample of predominantly Mexican American participants. Questionnaires assessing childhood maltreatment, family environment, and current psychological symptomatology were completed by 142 female undergraduates. Findings revealed that witnessing parental violence in childhood was associated with depressive symptoms, low self-esteem, and trauma symptoms in adulthood, even after controlling for child physical and sexual abuse. However, in subsequent analyses, also controlling for levels of nonphysical family conflict, previous associations between exposure to parental violence and adult symptomatology were reduced, such that trauma-related symptoms remained the sole outcome still predicted by a history of witnessing parental violence. Implications of these findings, issues related to the use of statistical control procedures in abuse effects research, and directions for future investigation are discussed.
\end{abstract}

KEY WORDS: exposure to domestic violence; trauma; child maltreatment; childhood sexual abuse.

During the past two decades, domestic violence has been increasingly recognized as a severe social problem in this country. It has been estimated that 2.3 million adults are physically or sexually assaulted by a romantic partner each year in theUnited States (Tjaden \& Thoennes, 1998), and that 3.3 to 10 million children may be exposed to these acts of violence (Carlson, 1984; Straus, 1992). In fact, studies suggest that as many as $33 \%$ of children witness domestic violence at some point during childhood, with many being exposed to repeated abusive incidents (Straus, 1992).

Systematic study of the possible effects of witnessing interparental aggression did not begin until the 1970s, as an outgrowth of broader investigations of domestic violence (e.g., Levine, 1975; Straus et al., 1980). Efforts to understand the immediate and long-term consequences of growing up in a violent home continue to be a burgeoning area within family violence research. In particu- lar, the potential short-term impact that interparental violence may have on children has received increased attention in recent years (for reviews see Carlson, 2000; Margolin, 1998; Margolin \& Gordis, 2000). As a whole, this work suggests that witnessing interparental violence is a risk factor for a variety of behavioral, emotional, and interpersonal difficulties among both children and adolescents. Depression, trauma-related symptoms, and low self-esteem are among the difficulties that have been linked to the childhood experience of witnessing parental violence (Hughes \& Luke, 1998; Kilpatrick \& Williams, 1998; Sternberg et al., 1993).

Given the range of emotional and behavioral problems manifested in children exposed to domestic violence, a critical question becomes whether these individuals continue to experience psychological difficulties into adulthood. To date, however, comparatively little research attention has focused on the functioning of adults 
who witnessed parental violence as children. Much of the literature that does include adults has concentrated on the intergenerational transmission of violence. These studies suggest that exposure to domestic violence in childhood may be a risk factor for involvement in abusive relationships as an adult (e.g., Cappell \& Heiner, 1990; Doumas et al., 1994). Such findings are consistent with a social learning perspective, which suggests that those who observe domestic violence as children learn that violent behavior is an acceptable form of conflict resolution in intimate relationships (Margolin, 1998).

The relatively scant literature examining psychological consequences of witnessing parental violence indicates that exposure to such events may lead to a range of mental health difficulties in adulthood. More specifically, women who report witnessing domestic violence as children have been found to be more depressed (ForsstromCohen \& Rosenbaum, 1985; Maker et al., 1998; Silvern et al., 1995), to have a lower self-esteem (Silvern et al., 1995), and to experience more trauma-related symptoms (Feerick \& Haugaard, 1999; Maker et al., 1998; Silvern et al., 1995) than do women without such histories. Researchers have used trauma theory (Silvern \& Kaersvang, 1989) and stress and coping theory (Lazarus \& Folkman, 1984) to explain the presence of increased internalizing symptoms in those who have witnessed violence. These theories suggest that exposure to violent altercations between family members can be trauma inducing due to the unpredictability, sudden onset, and high emotionality associated with these events (Margolin, 1998). Consequently, those with limited coping resources may exhibit trauma symptoms and other psychological difficulties lasting well into adulthood.

When considering the possible long-term impact of exposure to domestic violence, it is important to recognize that violence between spouses is likely to occur in the context of other forms of family dysfunction. For example, studies have documented that children from domestically violent homes are more likely to be victims of either physical or sexual abuse (Appel \& Holden, 1998; Jouriles et al., 1987; McCloskey et al., 1995). Presence of coexisting abuse types represents an obstacle to understanding the unique impact that exposure to domestic violence may have on adult functioning, because such events may themselves engender a range of long-term adjustment problems (see Malinosky-Rummell \& Hansen, 1993; Polusny \& Follette, 1995). Attempts to isolate adult correlates of exposure to parental violence, by statistically accounting for presence of childhood physical and sexual abuse, have resulted in mixed findings. In their sample of 287 female college students, Silvern et al. (1995) found that an initial relationship between childhood exposure to domestic violence and adult trauma symptoms became nonsignificant after controlling for childhood physical and sexual abuse, whereas depression and low self-esteem maintained associations with childhood exposure to violence. By contrast, Maker et al. (1998), using a sample of 131 college women, found that neither depression nor trauma symptoms remained related to domestic violence once childhood physical and sexual abuse had been controlled.

Nonviolent forms of family conflict (e.g., arguing, yelling, criticizing others) that undoubtedly pervade many violent homes may also pose a barrier to uncovering any unique correlates of exposure to domestic violence, for these incidents too have been linked to subsequent emotional and behavioral problems (Davies \& Cummings, 1994). Researchers attempting to account for these effects have typically controlled for levels of nonphysical conflict between spouses. Again, however, results have been inconsistent, with some studies finding a relationship between witnessing violence and adult psychological problems even after accounting for nonphysical forms of marital conflict (e.g., Henning et al., 1996, 1997), while others have reported no effects for witnessing after nonaggressive conflict between partners was covaried (e.g., Forsstrom-Cohen \& Rosenbaum, 1985).

The discrepant findings in the literature may be due to methodological variations across studies, such as differences in sample sizes and the ways in which witnessing of violence, child maltreatment, and family conflict have been defined and measured. For example, the Henning et al. (1996) sample was comprised of 617 women, whereas Forsstrom-Cohen and Rosenbaum's (1985) sample consisted of only 167 participants. Such discrepant sample sizes may result in differential abilities to detect group differences. An example of a definitional variation comes from Maker et al. (1998) who defined exposure to domestic violence as seeing or hearing violent acts between two caregivers before the age of 16; similarly physical and sexual abuse in this study was limited to acts that occurred to victims before 16 years of age. By contrast, Feerick and Haugaard (1999) classified only those who had actually seen (not just heard) a physical altercation between their parents prior to age 18 as having been exposed to violence; they also used 18 rather than 16 as the upper age limit for acts to be considered childhood sexual or physical abuse.

\section{Sampling Considerations}

Another important step in elucidating the relation- 
ship between childhood exposure to violence and adult psychological functioning involves broadening the range of samples in which these phenomena are examined. Obviously, findings that are similar across studies employing samples of varying demographic characteristics (e.g., ethnicity, socioeconomic status, etc.) are useful in making generalizations to a broad range of populations. Evidence of cultural differences in norms and beliefs regarding the use of violence (Kantor et al., 1994), as well as ethnic variations in the ways that victims understand and label experiences with violence (Sternberg, 1993), further highlight the need to examine relations between witnessing domestic violence and mental health outcomes across ethnically diverse samples.

Although many authors have recognized the need to include different ethnic and cultural groups in family violence research, the emerging literature on exposure to domestic violence remains lacking in this regard (Margolin, 1998). The present study seeks to address this need through use of a multicultural sample consisting primarily of Mexican American college students. Individuals of Hispanic descent currently represent $12 \%$ of the United States population, a figure that has increased dramatically in recent years (Therrien \& Ramirez, 2000). Those of Mexican origin make up the largest subgroup of Hispanic Americans, accounting for $66.1 \%$ of this population in the U.S. (Therrien \& Ramirez, 2000). Moreover, research suggests that domestic violence occurs at a particularly high rate among Mexican American families, suggesting that a large number of these individuals may be exposed to interparental aggression during childhood (Straus \& Smith, 1990). These changing demographics, coupled with the significant occurrence of domestic violence in Mexican American households, underscore the importance of expanding research on exposure to violence in this steadily increasing segment of our society.

\section{Summary and Expected Findings}

In summary, the present study has two primary objectives, the first of which is to further examine the adult psychological correlates associated with having witnessed parental violence as a child. In doing so, we attempt to isolate the relationship between exposure to domestic violence as a child and adult psychological functioning, by statistically controlling the relative contributions of several family environment variables (child physical and sexual abuse, nonphysical family conflict). The second objective involves broadening the scope of research on the correlates of witnessing domestic violence, by extending investigation to a predominately Latina sample.
Based on previous research (e.g., Forsstrom-Cohen \& Rosenbaum, 1985; Silvern et al., 1995), we anticipated finding bivariate relationships between reported childhood exposure to domestic violence and a range of adult psychological outcomes. In particular, we expected that witnessing domestic violence would be associated with increased depression, lower self-esteem, and more trauma-related symptoms. In addition to these bivariate associations, we also expected that a history of exposure to domestic violence would be uniquely associated with adult symptomatology, beyond that which could be attributed to other factors such as child maltreatment and nonphysical family conflict. Finally, the theoretical notion that witnessing interparental violence represents a traumatic stressor suggests that, among the outcome measures considered here, trauma symptomatology would retain the strongest association with childhood exposure to violence.

\section{METHOD}

\section{Participants}

Participants were 142 female undergraduates recruited from psychology classes on the campus of a private nearly all-female university in south central Texas. Participants ranged in age from 18 to 50 years, with a mean age of $23.57(S D=8.25)$. The ethnic composition of the sample was $80 \%$ Mexican American, $11 \%$ White, $6 \%$ African American, $1 \%$ Native American, $1 \%$ Asian, and $1 \%$ Other. Ninety-one percent reported that they were not married at the time of the study (i.e., they had never been married, nor were they cohabiting or currently separated or divorced), while $9 \%$ were married at the time of the study. Socioeconomic status was assessed using the Hollingshead Index (Hollingshead, 1975), which ranged from 8.00 to 66.00 with a mean of $37.83(S D=$ 11.99 ), indicating the sample was predominantly of a middle socioeconomic status.

\section{Measures}

Child Maltreatment Interview Schedule-Short Form (CMIS -SF; Briere,1992)

The CMIS-SF is a self-report interview that assesses several areas of childhood experiences including domestic violence, parental substance abuse, parental physical and psychological availability, psychological abuse, emotional abuse, physical abuse, sexual abuse, and perceptions of abuse status. The CMIS-SF sections used in 
the present study include those assessing childhood experiences of witnessing domestic violence, physical abuse, and sexual abuse. Using the CMIS-SF, each type of abuse was determined to be present or not present in accordance with the following definitions derived from this measure. Participants who reported seeing one parent hit or beat up their other parent before age 17 were considered to have witnessed domestic violence. Participants who reported that, before age 17, a parent did something to them on purpose (i.e., hit, punched, cut, or pushed them down), which made them bleed, gave them bruises or scratches, or broke their bones or teeth, were considered victims of childhood physical abuse. Participants who reported sexual touching, sexual kissing, or oral, anal, or vaginal penetration before the age of 17 with a family member or a person who was five or more years older were considered victims of sexual abuse.

\section{Trauma Symptom Checklist-40}

(TSC -40; Briere \& Runtz,1989; Elliot \& Briere,1992)

The TSC-40 is a 40-item self-report research instrument designed to assess symptomatology arising from childhood or adult traumatic experiences. It measures posttraumatic stress as well as other symptom clusters found in many traumatized individuals. Each symptom item is rated according to its frequency of occurrence over the prior 2 months using a 4-point scale ranging from $0=$ never to $3=$ often. Studies utilizing the TSC-40 indicate that alpha coefficients for the total scale score average between 0.89 and 0.91 . Predictive validity of the TSC-40 and its previous version, the TSC-33, has been demonstrated with reference to a wide variety of traumatic experiences (Elliot \& Briere, 1992; Maker et al., 2001). Convergent validity and discriminant validity has also been demonstrated on the total score of the TSC-40 (Zlotnick et al., 1996). The alpha reliability coefficient for the TSC-40 was 0.91 in the present sample.

\section{The Self-Rating Depression Scale (SDS; Zung, 1965)}

The SDS is a 20-item self-report instrument developed to examine cognitive, affective, psychomotor, somatic, and social-interpersonal symptoms of depression. The SDS is composed of 10 items, which are worded in a negative direction (e.g., "I feel downhearted, blue, and sad.") and 10 items worded in a positive direction (e.g., "I find it easy to do the things I used to."). Respondents are asked to rate each item on a 4-point scale ranging from $1=$ some or little of the time to $4=$ most or all of the time. The SDS is scored by summing the item ratings to produce a raw score ranging from 20 to 80 . The SDS has been shown to have adequate reliability and validity for both research and diagnostic purposes (e.g., Biggs et al., 1978; Gabrys \& Peters, 1985). The alpha reliability coefficient for the SDS was 0.79 in the present sample.

\section{The Rosenberg Self-Esteem Scale}

(RSE; Rosenberg, 1979)

The RSE is a 10-item Guttman scale originally designed to measure self-esteem in various groups and occupations. The scale includes items worded both positively (e.g.,"On the whole, I am satisfied with myself.") and negatively (e.g., "I feel that I do not have much to be proud of."). Respondents rate each item on a 4-point scale ranging from $1=$ strongly agree to $4=$ strongly disagree. Higher scores on the RSE are indicative of lower self-esteem. The RSE has excellent internal consistency, and test-retest reliability data reveal excellent correlations of 0.85 and 0.88 ; validity is supported by studies demonstrating its concurrent, predictive, and construct validity (see Corcoran \& Fisher, 2000). The alpha reliability coefficient for the RSE was 0.88 in the present sample.

\section{Family Environment Scale (FES; Moos \& Moos, 1986)}

The Family Environment Scale is a self-report questionnaire designed to assess interpersonal relationships among family members, directions of personal growth emphasized by the family, and the basic organizational structure of the family. The FES is one of the most common assessment instruments used in marital and family research (Piotrowski, 1999). The FES consists of 90 true-false items, which fall into 10 subscales. Only the Conflict subscale was used in the present study. The Conflict sub-scale measures the extent to which the open expression of anger and generally conflicted interactions are characteristic of the family. Some examples of items in the Conflict subscale are: "Family members often criticize each other," "We fight a lot in our family," "Family members hardly ever lose their temper in our family," and "In our family, we believe you don't ever get anywhere by raising your voice." The alpha coefficient for the FES Conflict subscale was 0.69 in the present sample.

\section{Procedure}

All self-report data were obtained as a part of a project examining the adult correlates of childhood maltreat- 
ment. Data were collected during scheduled times outside of regular class hours. Questionnaires were administered at group sessions by trained research assistants. After informed consent was obtained, participants completed the CMIS-SF, TSC-40, SDS, RSE, FES, and demographic information, as well as several other instruments not included in the present study. Measures were administered to participants in a random order. This research was conducted in accordance with American Psychological Association (APA) ethical guidelines (APA, 1992).

\section{RESULTS}

\section{Rates of Witnessing Violence}

Forty-five women (32\%) reported that, before they were age 17, they had seen one of their parents hit or beat up their other parent. Of those who endorsed witnessing violence between their parents, $18 \%$ reported witnessing only one incident of domestic violence, $42 \%$ reported 2-5 incidents, 4\% reported 6-9 incidents, and $16 \%$ reported 10 or more incidents. Nine participants ( $20 \%$ of those who witnessed domestic violence) did not report the number of violent incidents they had witnessed. The number of domestic violence incidents witnessed by this group of women ranged from 1 to 100 , with a mean of 7.61 incidents $(S D=16.73)$. Of the 45 women exposed to domestic violence, $40 \%(n=18)$ reported witnessing only their father hit their mother, 13\% $(n=6)$ reported witnessing only their mother hit their father, and $47 \%(n=21)$ reported witnessing both their father and mother hit each other. Forty-nine percent ( $n$ $=23$ ) of those who witnessed domestic violence reported that medical treatment was required as a result of a physical assault between their parents.

\section{Demographic Comparisons}

To determine if the women who witnessed domestic violence differed demographically from the women who did not, chi-square and $t$-test analyses were conducted for age, ethnicity, and Hollingshead SES scores. The two groups did not differ with regard to age, $t(132)=0.015$, $p=0.988$, or ethnicity, $\chi^{2}(5)=4.01, p=0.548$; however, they did significantly differ on Hollingshead SES scores, $t(135)=3.10, p=0.002$. Women who witnessed domestic violence had lower Hollingshead SES scores $(M=$ $33.35, S D=12.08)$ than women who did not witness domestic violence $(M=39.95, S D=11.40)$. To statistically control for this difference, Hollingshead SES scores were entered in subsequent regression models.
Table I. Means and Standard Deviation of Adult Psychological Functioning Variables

\begin{tabular}{lrrrrr}
\hline & \multicolumn{2}{c}{$\begin{array}{c}\text { Witnessed domestic } \\
\text { violence }\end{array}$} & & \multicolumn{2}{c}{$\begin{array}{c}\text { Did not witness } \\
\text { domestic violence }\end{array}$} \\
\cline { 2 - 3 } \cline { 5 - 6 } Measure & Mean & SD & & Mean & SD \\
\hline TSC-40 & 37.55 & 18.18 & & 28.53 & 14.88 \\
RSE & 19.24 & 5.74 & & 17.16 & 4.90 \\
SDS & 40.53 & 7.82 & & 37.07 & 7.25 \\
\hline
\end{tabular}

Note. TSC-40 $=$ Trauma Symptom Checklist-40; RSE $=$ Rosenberg Self-Esteem Scale; SDS = Self-Rating Depression Scale. Higher scores $=$ endorsement of more trauma symptoms, lower self-esteem, and endorsement of more depressive symptoms.

\section{Data Analytic Strategy}

As noted, a primary purpose of the present study was to examine the independent empirical relationship between adult psychological functioning and a history of having witnessed domestic violence in childhood. To address the potential confounding effects of childhood physical abuse, sexual abuse, and nonphysical forms of family conflict - each of which has been linked to both domestic violence and adult symptomatology-it was necessary to partial variance associated with these variables during analyses. Multiple hierarchical regression analyses were conducted to accomplish this objective, with particular attention paid to the squared semipartial correlations for relevant predictors at each step. The squared semipartial correlation is the best statistic to assess the unique relationship between individual predictor variables and a criterion (Tabachnick \& Fidell, 1996).

\section{Witnessing Violence and Adult Symptomatology}

Means and standard deviations for the RSE, SDS, and TSC-40 are presented in Table I. Women who witnessed domestic violence reported lower self-esteem and endorsed more depressive and trauma symptoms than those women who did not witness domestic violence.

To examine the simple relationship between exposure to domestic violence and current adult functioning while controlling for socioeconomic status, Hollingshead SES scores and witnessing domestic violence (coded as $0=$ did not witness violence, $1=$ witnessed $)$ were entered into three separate multiple regression analyses, using the three adult psychological functioning measures (i.e., self-esteem, depressive symptoms, and trauma symptoms) as the criterion variables. Results for the 
Table II. Relationship of Witnessing Domestic Violence and Adult Psychological Functioning

\begin{tabular}{|c|c|c|c|c|c|c|}
\hline & \multicolumn{2}{|c|}{ RSE } & \multicolumn{2}{|c|}{ SDS } & \multicolumn{2}{|c|}{ TSC-40 } \\
\hline & $\beta$ & $s r^{2}$ & $\beta$ & $s r^{2}$ & $\beta$ & $s r^{2}$ \\
\hline SES & 0.059 & 0.003 & 0.061 & 0.003 & -0.002 & 0.000 \\
\hline Witnessed domestic violence & 0.183 & $0.031^{*}$ & 0.227 & $0.048^{*}$ & 0.251 & $0.059^{* *}$ \\
\hline$R^{2}$ & \multicolumn{2}{|c|}{0.031} & \multicolumn{2}{|c|}{$0.048^{*}$} & \multicolumn{2}{|c|}{$0.063^{*}$} \\
\hline
\end{tabular}

Note. RSE, Rosenberg Self-Esteem Scale; SDS, Self-Rating Depression Scale; TSC-40,Trauma Symptom Checklist- 40 .

${ }^{* *} p<0.05 .{ }^{* *} p<0.01$.

three adult functioning variables are shown in Table II. Witnessing domestic violence was found to significantly predict, in a negative direction, all three outcome variables.

\section{Witnessing Violence, Child Maltreatment, and Adult Symptomatology}

Having found a simple relationship between witnessing domestic violence and adult psychological functioning, we proceeded with additional regression analyses to assess the unique association between these experiences and adult symptomatology, beyond that attributable to childhood physical and sexual abuse. To examine this relationship, childhood sexual and physical abuse, as well as SES, were entered into a regression model first, followed by the witnessing domestic violence variable. The squared semipartial correlations showing the unique contribution of witnessing domestic violence are shown in Table III. A very similar pattern of findings was revealed in that the witnessing variable continued to predict adult functioning across all three measures of adult functioning (trauma symptoms, depressive symptoms, and self-esteem), beyond that which was explained by the other forms of child maltreatment. The unique variance accounted for by witnessing domestic violence ranged from $3 \%$ to $5.7 \%$ across the three outcome variables. It is interesting to note, however, that neither childhood physical nor sexual abuse significantly predicted trauma-related symptoms, depressive symptoms, or poor self-esteem in adulthood.

\section{Witnessing Violence, Nonphysical Family Conflict, and Adult Symptomatology}

Because the significant relationship between witnessing domestic violence and adult psychological functioning was maintained in the presence of child maltreatment, the FES Conflict subscale scores were added to a subsequent multiple regression model, thus providing the most stringent test of the relative contribution of witnessing domestic violence to adult psychological functioning. As shown in Table IV, this model revealed that witnessing domestic violence maintained its predictive relationship with the TSC-40 (trauma symptoms), but not with the RSE (self-esteem) or the SDS (depressive symptoms). That is, after controlling for all types of family dysfunction assessed (childhood physical and

Table III. Relationship of Witnessing Domestic Violence and Adult Psychological Functioning After Controlling for Childhood Physical and Sexual Abuse

\begin{tabular}{|c|c|c|c|c|c|c|}
\hline & \multicolumn{2}{|c|}{ RSE } & \multicolumn{2}{|c|}{ SDS } & \multicolumn{2}{|c|}{ TSC-40 } \\
\hline & $\beta$ & $s r^{2}$ & $\beta$ & $s r^{2}$ & $\beta$ & $s r^{2}$ \\
\hline SES & 0.059 & 0.003 & 0.046 & 0.002 & -0.003 & 0.000 \\
\hline Physical abuse & -0.021 & 0.000 & -0.086 & 0.007 & -0.070 & 0.005 \\
\hline Sexual abuse & 0.023 & 0.000 & -0.008 & 0.000 & 0.069 & 0.004 \\
\hline Witnessing domestic violence & 0.182 & $0.030^{*}$ & 0.237 & $0.052^{* *}$ & 0.250 & $0.057^{* * *}$ \\
\hline$R^{2}$ & \multicolumn{2}{|c|}{0.032} & \multicolumn{2}{|c|}{0.056} & \multicolumn{2}{|c|}{$0.072^{*}$} \\
\hline
\end{tabular}

Note. RSE, Rosenberg Self-Esteem Scale; SDS, Self-Rating Depression Scale; TSC-40, Trauma Symptom Checklist-40.

${ }^{*} p<0.05{ }^{*} p<0.01$. 
Table IV. Relationship of Witnessing Domestic Violence and Adult Psychological Functioning After Controlling for Childhood Physical and Sexual Abuse and Nonphysical Family Conflict

\begin{tabular}{|c|c|c|c|c|c|c|}
\hline & \multicolumn{2}{|c|}{ RSE } & \multicolumn{2}{|c|}{ SDS } & \multicolumn{2}{|c|}{ TSC-40 } \\
\hline & $\beta$ & $s r^{2}$ & $\beta$ & $s r^{2}$ & $\beta$ & $s r^{2}$ \\
\hline SES & 0.099 & 0.009 & 0.007 & 0.005 & 0.036 & 0.001 \\
\hline Physical abuse & -0.032 & 0.001 & -0.099 & 0.009 & 0.083 & 0.007 \\
\hline Sexual abuse & 0.024 & 0.000 & -0.007 & 0.000 & 0.074 & 0.002 \\
\hline FES conflict & 0.220 & $0.042^{*}$ & 0.166 & 0.024 & 0.159 & 0.025 \\
\hline Witnessing domestic violence & 1.172 & 0.009 & 0.177 & 0.026 & 0.172 & $0.030^{*}$ \\
\hline$R^{2}$ & \multicolumn{2}{|c|}{0.075} & \multicolumn{2}{|c|}{0.079} & \multicolumn{2}{|c|}{$0.095^{*}$} \\
\hline
\end{tabular}

Note. RSE, Rosenberg Self-Esteem Scale; SDS, Self-Rating Depression Scale; TSC-40, Trauma Symptom Checklist-40.

${ }^{*} p<.05$,

sexual abuse as well as nonviolent family conflict) trauma symptomatology was the strongest and most statistically significant correlate of childhood exposure to parental violence.*

\section{DISCUSSION}

The primary objective of the present study was to examine the adult psychological correlates of childhood exposure to parental violence. Although similar longterm sequelae have been studied previously (e.g., Silvern et al., 1995), the current investigation extends these findings by utilizing a more ethnically diverse sample and by statistically controlling for other forms of child maltreatment and general levels of family dysfunction in a sequential fashion during analyses. Our results were fairly consistent with other studies (e.g., Henning et al., 1996; Silvern et al., 1995) showing that childhood exposure to violence may be related to various adverse adult outcomes beyond that attributable to concomitant childhood sexual and physical abuse. This pattern of findings suggests that witnessing interparental violence as a youth may contribute to outcomes such as lowered self-esteem, increased depression, and greater trauma symptoms, independent of other childhood abuse experiences.

However, when the correlates of witnessing violence were further isolated in subsequent analyses controlling for levels of nonviolent family conflict (e.g., arguing, expression of anger, criticism, lack of support), results revealed that elevated trauma symptoms were the

\footnotetext{
*In order to determine whether the presence of non-Mexican Americans altered the overall patter of results, we replicated our analyses with only the data from Mexican American participants. These findings were identical to those presented using the entire sample, with one minor exception. After controlling for childhood physical and sexual abuse and nonphysical family conflict, the squared semipartial correlation between witnessing and trauma symptoms was just shy of statistical significance $(p=0.056)$.
}

sole outcome variable to maintain an association with early exposure to violence. This finding of increased trauma symptomatology among those witnessing parental violence is consistent with other data (Feerick \& Haugaard, 1999), and further supports the notion that early experiences of this type may be conceptualized as traumatic stressors with the potential to leave a lasting impact on victims. Consistent with trauma theory, it has been noted that the unpredictability, sudden onset, and high emotional intensity of witnessing one parent physically assault another resembles other known trauma-producing events, and may be distinct from other forms of adversity experienced by children (Margolin, 1998).

Although not our primary focus, it is interesting to note that we did not find significant relationships between childhood physical or sexual abuse and adult psychological distress in the form of increased depression, trauma symptoms, or impaired self-esteem. This finding is inconsistent with large bodies of literature on the long-term correlates of both sexual and physical abuse (see Malinosky-Rummell \& Hansen, 1993; Polusny \& Follette, 1995 for reviews). There could be several reasons for this inconsistency. First, we cannot rule out that the present sample was anomalous in some unknown fashion, or that its ethnic diversity relative to most other studies may have contributed to our divergent findings. For example, several authors have postulated that some characteristics of Hispanic culture such as a strong extended family, community ties, and the importance of the religion may protect women from the negative psychological consequences of child maltreatment by providing a supportive environment and a sense of healing in the aftermath of abuse (Sorenson \& Siegel, 1992; Sue \& Sue, 1999). On the other hand, although many child maltreatment studies have considered general characteristics of family environment (e.g., substance abuse, parental warmth, conflict) as possible contributors to the 
long-term dysfunction found among abuse survivors (e.g., Alexander \& Lupfer, 1987), few have simultaneously evaluated the possibility that physical or sexual abuse survivors may have also witnessed interparental violence. The present findings that a childhood history of witnessing family violence was more predictive of adult distress than were other forms of child maltreatment highlight the importance of considering coexisting abuse types in future research.

Several limitations of the present study should be noted. One of these concerns the retrospective nature of the data collection. As with all retrospective research, participants may provide inaccurate or distorted information regarding stressful events occurring during childhood. Although this study attempted to safeguard against conscious suppression of family violence experiences by using anonymous participation, the possibility of distortions in recall still exists. Similarly, because of the anonymous nature of the study, it was not feasible to obtain corroborating reports of family violence from parents, siblings, or law enforcement. In addition, although this study extends previous findings to a more ethnically diverse sample, the usual constraints associated with the limited demographic variability of college samples still apply. That is, because the study was conducted with female college students, the findings may not be applicable to the broader Mexican American population or to males. Further, given the large number of Hispanic youth that drop out of high school (National Center for Educational Statistics, 1997), it is possible that a college sample of Mexican Americans may significantly differ from their counterparts who do not attend college.

A final issue concerns the nature of our design and use of statistical control to isolate the potential mental health correlates of witnessing domestic violence. Because of the retrospective, correlational nature of the study, conclusions regarding causality cannot be made. Further, because domestic violence undoubtedly stems, in part, from a generally negative family environment, statistically separating these phenomena is to some extent an artificial exercise. As Briere et al. (1988; Briere \& Elliot, 1993) have cautioned, interpretation of data partialled in this manner may be misleading and can provide a conservative estimate of the relationship between a particular form of childhood abuse and its longterm correlates. The partialling procedures used here could have various implications for our findings. On one hand, statistically controlling potential third variables may have "wiped out" actual associations between child exposure to domestic violence and two of our outcome variables (depressive symptoms and low self-esteem).
On the other hand, the fact that reports of witnessing violence continued to predict adult trauma symptoms, despite the use of rather stringent statistical procedures, suggests that this may be a fairly robust relationship.

The present study contributes to the growing body of literature addressing the lasting correlates of witnessing domestic violence as a child. More specifically, by examining this issue in a predominately Latina sample, this investigation adds to emerging evidence suggesting that witnessing parental violence as a child may lead to mental health difficulties in later life. Nevertheless, given the methodological limitations associated with attempting to statistically disentangle the multiple factors that may contribute to these long-term difficulties, future researchers should consider alternative approaches to examining the long-term correlates of childhood exposure to violence. In particular, investigators should consider multigroup designs incorporating participants who differ with regard to the presence of overt parental violence, but are matched on levels of non-violent family conflict, other forms of child abuse, and significant demographic variables. Such studies could help further clarify any unique association between exposure to parental violence and adult psychological distress. In the treatment realm, the present findings that childhood exposure to violence may be strongly associated with trauma-related symptoms should alert clinicians to the potential etiological significance of these experiences in planning interventions.

\section{REFERENCES}

Alexander, P. C., and Lupfer, M. A. (1987). Family characteristics and long-term consequences associated with sexual abuse. Arch. Sex Behav. 16: 235-245.

American Psychological Association (1992). Ethical principles of psychologists and code of conduct. Am. Psychol. 47: 1597-1611.

Appel, A. E., and Holden, G. W. (1998). The co-occurrence of spouse and physical child abuse: A review and appraisal. J. Fam. Psychol. 12: $578-599$.

Biggs, J. T., Wylie, L. T., and Ziegler, V. E. (1978). Validity of the Zung self-rating depression scale. Br. J. Psychiatry 132: 381-385.

Briere, J. (1988). Controlling for family variables in abuse effects research: A critique of the 'partialling' approach. J. Interper. Violence 3: 80-89.

Briere, J. (1992). Child Abuse Trauma: Theory and Treatment of the Lasting Effects, Sage, Newbury Park, CA.

Briere, J., and Elliot, D. M. (1993). Sexual abuse, family environment, and psychological symptoms: On the validity of statistical control. $J$. Consult. Clin. Psychol. 61: 284-288.

Briere, J., and Runtz, M. (1989) The Trauma Symptom Checklist (TSC40-33): Early data on a new scale. J. Interpers. Violence 4: 151-163.

Cappell, C., and Heiner, R. B. (1990). The intergenerational transmission of family aggression. J. Fam. Violence 5: 135-152. Carlson, B. E. (1984). Children's observations of interparental violence. In Roberts A. R. (ed.), Battered Women and Their Families, Springer, New York, pp. 147-167. 
Carlson, B. E. (2000). Children exposed to intimate partner violence. Trauma Violence Abuse 1: 321-342.

Corcoran, K., and Fischer, J. (2000). Measures for Clinical Practice (Vol. 1). The Free Press, New York.

Davies, P. T., and Cummings, E. M. (1994). Marital conflict and child adjustment: An emotional security hypothesis. Psychol. Bull. 116: 387411.

Doumas, D., Margolin, G., and John, R. S. (1994). The intergenerational transmission of aggression across three generations. J. Fam. Violence 9: 157-175.

Elliott, D. M., and Briere, J. (1992) Sexual abuse trauma among professional women: Validating the trauma symptom checklist-40 (TSC40). Child Abuse Negl. 16: 391-398.

Feerick, M. M., and Haugaard, J. J. (1999). Long-term effects of witnessing marital violence for women: The contribution of childhood physical and sexual abuse. J. Fam. Violence 14: 377-398.

Forsstrom-Cohen, B., and Rosenbaum, A. (1985). The effects of parental marital violence on young adults: An exploratory investigation. $J$. Marriage Fam. 47: 467-471.

Gabrys, J. B., and Peters, K. (1985). Reliability, discriminant and predictive validity of the Zung self-rating depression scale. Psychol. Rep. 57: 1091-1096.

Henning, K., Leitenberg, H., Coffey, P., Bennett, T., and Jankowski, M. K. (1997). Long-term psychological adjustment to witnessing interparental physical conflict during childhood. Child Abuse Negl. 21: 501-515.

Henning, K., Leitenberg, H., Coffey, P., Turner, T., and Bennett, R. T. (1996). Long-term psychological and social impact of witnessing physical conflict between parents. J. Interpers. Violence 11: 35-51.

Hollingshead, A. B. (1975). Four factor index of social status. Unpublished Manuscript, Yale University.

Hughes, H. M., and Luke, D. A. (1998). Heterogeneity in adjustment among children of battered women. In Holden, G. W., Geffner, R., and Jouriles, E. N. (eds.), Children Exposed to Marital Violence: Theory, Research, and Applied Issues, American Psychological Association, Washington, DC, pp. 185-221.

Jouriles, E. N., Barling, J., and O'Leary, K. D. (1987). Predicting child behavior problems in maritally violent families. J. Abnorm. Child Psychol. 15: 165-173.

Kantor, K. G., Jasinski, J. L., and Aldarondo, E. (1994). Sociocultural status and incidence of marital violence in Hispanic families. Violence Vict. 9: 207-222.

Kilpatrick, K. L., and Williams, L. M. (1998). Potential mediators of post-traumatic stress disorder in child witnesses to domestic violence. Child Abuse Negl. 22: 319-330.

Lazarus, R., and Folkman, S. (1984). Stress, Appraisal, and Coping, Springer, New York.

Levine, M. D. (1975). Interpersonal violence and its effects on the children: A study of 50 families in general practice. Med. Sci. Law 15: 172-176.

Maker, A. H., Kemmelmeier, M., and Peterson, C. (1998). Long-term psychological consequences in women of witnessing parental physical conflict and experiencing abuse in childhood. J. Interpers. Violence 13: 574-589.

Maker, A. H., Kemmelmeier, M., and Peterson, C. (2001). Child sexual abuse, peer sexual abuse, and sexual assault in adulthood: A multirisk model of revictimization. J. Trauma. Stress 14: 351-368.

Malinosky-Rummell, R., and Hansen, D. J. (1993). Long-term consequences of childhood physical abuse. Psychol. Bull. 114: 68-79.

Margolin, G. (1998). Effects of domestic violence on children. In Trickett P. K., and Schellenbach C. J. (eds.), Violence Against Children in the Family and the Community, American Psychological Association, Washington, DC, pp. 57-101.
Margolin, G., and Gordis, E. B., (2000). The effects of family and community violence on children. Annu. Rev. Psychol. 51: 445-479.

McCloskey, L. A., Figueredo, A. J., and Koss, M. P. (1995). The effects of systemic family violence on children's mental health. Child Dev. 66: 1239-1261.

Moos, R. H., and Moos, B. S. (1986). Family Environment Scale Manual, Consulting Psychologists, Palo Alto, CA.

National Center for Educational Statistics (1997). Dropout rates in the United States: 1995 (NCES Publication No. 97-473). Retrieved July 29, 2002, from http://nces.ed.gov/pubs/dp95/

Piotrowski, C. (1999). Use of tests and measures in marital and family research. Psychol. Rep. 84: 1251-1252.

Polusny, M. M., and Follette, V. M. (1995). Long-term correlates of childhood sexual abuse: Theory and empirical findings. Appl. Prev. Psychol. 4: 143-166.

Silvern, L., and Kaersvang, L. (1989). The traumatized children of violent marriages. Child Welfare 68: 421-436.

Silvern, L., Karyl, J., Waelde, L., Hodges, W. F., Starek, J., Heidt, E., and Min, K. (1995). Retrospective reports of parental partner abuse: Relationships to depression, trauma symptoms and self-esteem among college students. J. Fam. Violence 10: 177-202.

Sorenson, S. B., and Siegel, J. M. (1992). Gender, ethnicity, and sexual assault: Findings from a Los Angeles study. J. Soc. Issues 48: 93104.

Sternberg, K. J. (1993). Child maltreatment: Implications for policy from cross-cultural research. In Cicchetti, D., and Toth, S. L. (eds.), Child Abuse, Child Development, and Social Policy: Advance in Applied Developmental Psychology, Vol. 8, Ablex, Norwood, NJ, pp. 191212.

Sternberg, K. J., Lamb, M. E., Greenbaum, C., Cicchetti, D., Dawud, S., Cortes, R. M., Krispin, O., and Lorey, F. (1993). Effects of domestic violence on children's behavior problems and depression. Dev. Psychol. 29: 44-52.

Straus, M. A. (1992). Children as witnesses to marital violence: A risk factor for lifelong problems among a nationally representative sample of American men and women. In Schwarz D. F. (ed.), Children and Violence: Report of the Twenty-Third Roundtable on Critical Approaches to Common Pediatric Problems, Ross Laboratories, Columbus, OH, pp. 98-109.

Straus, M. A., Gelles, R. J., and Steinmetz, S. K. (1980). Behind Closed Doors, Anchor, Garden City, NY.

Straus, M. A., and Smith, C. (1990). Violence in Hispanic families in the United States: Incidence rates and structural interpretations. In Straus, M. A., and Gelles, R. J. (eds.), Physical Violence in American Families: Risk Factors and Adaptations to Violence in 8,145 Families, Transaction Publishers, New Brunswick, NJ, pp. 341-363.

Sue, D. W., and Sue, D. (1999). Counseling the Culturally Different: Theory and Practice, 3rd edn., Wiley \& New York. Tabachnick, B. G., and Fidell, L. (1996). Using Multivariate Statistics, 3rd edn., HarperCollins College Publisher, New York.

Therrien, M., and Ramirez, R. R. (2000). The Hispanic population in the United States: March 2000. Current Population Reports, P20-535, U.S. Census Bureau, Washington, DC. Retrieved June 13, 2001, from http://www.census.gov/prod/2001pubs/p20-535.pdf

Tjaden, P., and Thoennes, N. (1998). Prevalence, Incidence, and Consequence of Violence against Women: Findings from the National Violence Against Women Survey (NCJ 172837), U.S. Department of Justice, Washington, DC.

Zlotnick C., Shea, M. T., Begin, A., Pearlstein, T., Simpson, E., and Costello, E. (1996). The validation of the Trauma Symptom Checklist-40 (TSC-40) in a sample of inpatients. Child Abuse Negl. 20: 503-510. 